\title{
The public production and sharing of medical information. An Australian perspective
}

\author{
Henry C.H. Ko
}

\begin{abstract}
There is a wealth of medical information now available to the public through various sources that are not necessarily controlled by medical or healthcare professionals. In Australia there has been a strong movement in the health consumer arena of consumer-led sharing and production of medical information and in healthcare decision-making. This has led to empowerment of the public as well as increased knowledge-sharing. There are some successful initiatives and strategies on consumer-and public-led sharing of medical information, including the formation of specialised consumer groups, independent medical information organisations, consumer peer tutoring, and email lists and consumer networking events. With well-organised public initiatives and networks, there tends to be fairly balanced information being shared. However, there needs to be caution about the use of publicly available scientific information to further the agenda of special-interest groups and lobbying groups to advance often biased and unproven opinions or for scaremongering. With the adoption of more accountability of medical research, and the increased public scrutiny of private and public research, the validity and quality of medical information reaching the public is achieving higher standards.
\end{abstract}

\section{Background}

\section{Sources of medical information}

Medical information now available to the public through various sources that are not necessarily controlled by medical or healthcare professionals. This can be through the internet, non-governmental organisations, independent consumer organisations, and commercial sources. In Australia there has been an increase in user-led health and bioscience communication. In particular, there has been a strong movement in the health consumer arena of consumer-led sharing and production of medical information and in healthcare decision-making. This has led to empowerment of the public as well as increased knowledge-sharing. ${ }^{1,2}$

Traditional sources of medical knowledge have been through the expert-to-patient model, with the public tending to defer any decisions about medical issues to the medical experts at the top of the "knowledge hierarchy"., 3 This relied heavily on personal face-to-face contact with experts or visiting medical libraries to find research publications done by scientists, medical researchers and clinicians. However, with the increasing use of the internet as a source of information that is accessible to more and more people we have seen a flattening of the world. ${ }^{5}$ Combining the converging factors of increasingly busy healthcare professionals (clinicians, pharmacists, etc), the increasing free availability of health and medical information online (though NLM Medline, ${ }^{6} \mathrm{PloS},{ }^{7}$ and various free-access online journals and databases), the increasing thirst for knowledge of consumers and the public, we see the elements that have contributed to the user-led or consumer-led production and sharing of medical information.

In the author's opinion the open-access revolution and the embracing of this concept by the biomedical and healthcare research disciplines globally have made the creation of consumer-led production and sharing of medical information easier. This also points to the democratisation of information and 
elements of 'freedom of information'. The spread of user- or consumer-controlled medical information and content contributes to the strengthening of the information economy and democracy. ${ }^{8-10}$ The fact that consumers have relatively free access to information and knowledge created by society, and can engage with the parties that create the knowledge, is also a mark of democracy. ${ }^{8-10}$ Whether the sources are accurate and reliable and if consumer interpretations of the information are valid are entirely different questions that warrant further investigation. ${ }^{11-14}$

\section{User-led medical and bioscience communication in Australia}

This article reviews some of the successful initiatives and strategies on consumer- and public-led sharing of medical information in Australia, including the formation of specialised consumer groups that discuss medical information and policy, independent medical information organisations, consumer peer tutoring on medical issues, and email lists and consumer networking events. A feature of many of these strategies are that many of the participants are not medical or healthcare professionals yet are able to discuss in depth various medical and policy issues. Those of the public who are involved in medical issues communication are very adept in conceptualising and explaining the content and issues in their medical interest area. This in part stems from the high quality and "digestibility" of the information reaching the public that is shared between users, as well as the support structures and often personal motivations of the users that are involved in sharing the information. Figure 1 shows a simple representation of the inter-relationship between the various players who contribute to the user-led production and sharing of medical information.

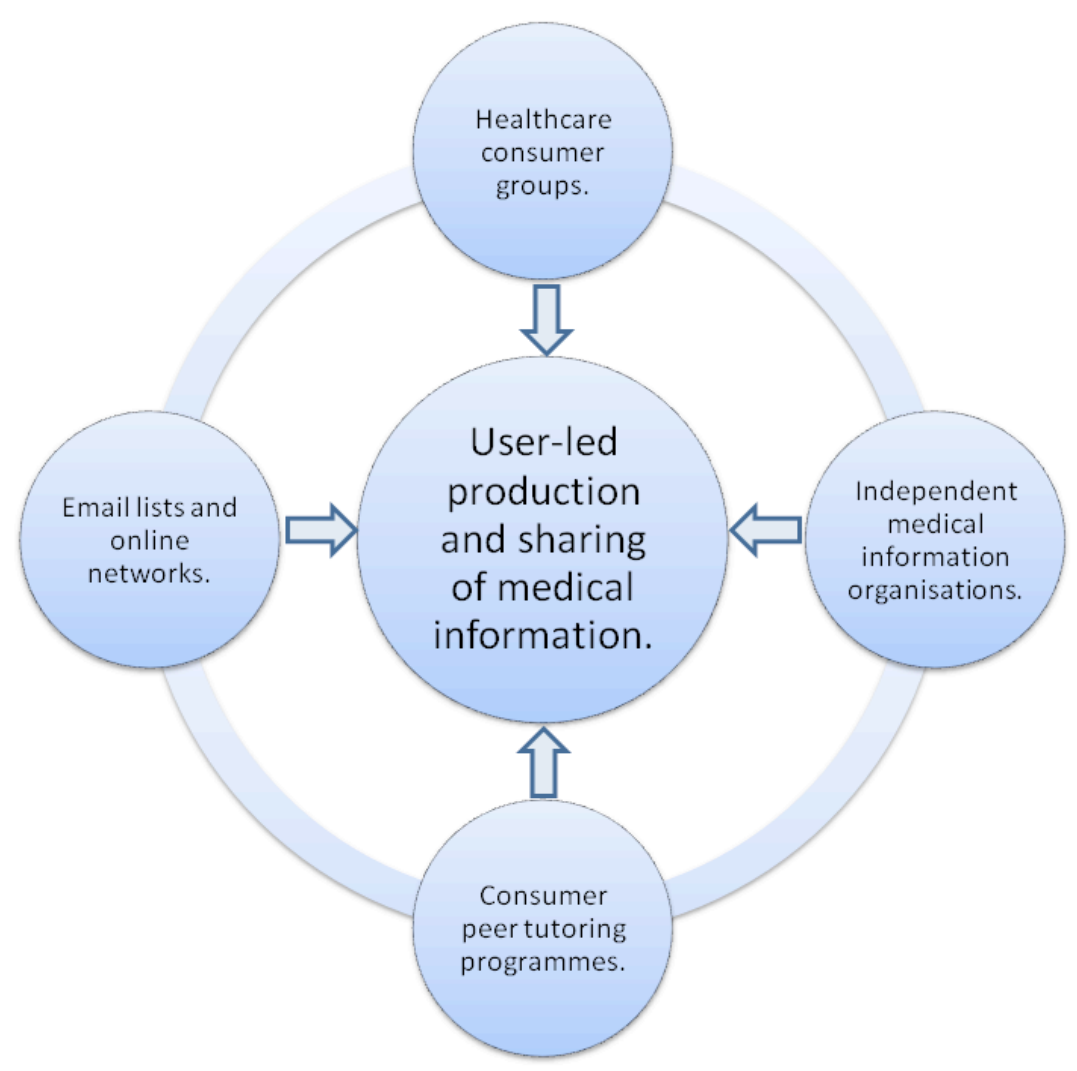

Figure 1. The inter-relationship of the various players in user-led production and sharing of medical information. All elements interact with each other continuously and contribute to the user-led production and sharing of medical information. 
This article is not focussing on the well developed field of health promotion, which is usually a topdown approach of experts or policy-makers teaching the public consumers, but on how technical medical and bioscience information is transferred within the public by consumers. Sometimes the medical information can be transferred in the other direction from the public/consumers to the experts - a "bottom-upwards" approach if you will. The workings of clusters of public and consumer-led communication based around specific interest groups (eg cancer) will also be discussed, as well as a discussion on some of the benefits and potential dangers of user-led science communication in the medical and bioscience arena. Something that many researchers in medical and health consumer engagement mention is that there is a lack of published literature on how user and consumers are using medical information. ${ }^{15}$ The recording, evaluation and publishing of the consumer engagement process and consumer-led medical communication is not systematically nor consistently done. Most of the information in this area is from knowledge of local initiatives or word of mouth. Many of the observations and reflective analysis presented here are from my own involvement in health and medical consumer groups. In this article I use the terms bioscience, medical and bioscientific interchangeably, but they are similar in meaning.

\section{Enablers of user-led medical and bioscience communication in Australia}

\section{Healthcare consumer groups}

With an increasing awareness of the healthcare system and in many cases a very personal interest in a specific disease or health condition, healthcare consumers are an excellent example of user-led science communication. In the author's own experience, healthcare consumers are articulate and knowledgeable about medical issues and policies. The community building of healthcare consumer groups helps to consolidate the medical and bioscience knowledge that the consumers have, but also help to increase their power in sharing this information to other new consumers and users (eg patients). In a bottom-up approach to information sharing, healthcare consumer groups can also influence and guide health and medical policy by advising governments and healthcare organisations in policy forums such as the National Medicines Symposium ${ }^{16}$ on the "Quality use of medicines" which was held in Canberra, Australia, in May 2008, the Second Joint Medicines Policy Conference ${ }^{17}$ which was held in Canberra, Australia, in November 2008, and consumer consultations with the Australian Commission on Quality and Safety in Healthcare. ${ }^{18,19}$ This is a unique position where we have the users and consumers of information influencing the top of the knowledge and organisational power hierarchy. Of course, there is variation in how public engagement in science is done and to what extent it can influence decision-making processes. ${ }^{20}$

Examples of health consumer groups in Australia consisting of users and consumers of health and medical information that are producing and sharing medical information include the Consumers Health Forum of Australia, ${ }^{21}$ Cancer Voices Australia ${ }^{22}$ and its state counterparts, and Health Consumer Councils. ${ }^{23}$ Smaller examples of user and consumer groups may be community support groups for specific illnesses where medical information is shared between a small number of people (eg arthritis support groups for the elderly in nursing homes). Table 1 lists some Australian healthcare consumer groups.

The success of health consumer groups for being user-led medical and bioscience communication organisations in Australia lies in the involved individuals' intrinsic and high level of personal affinity to the organisation's causes. This is usually due to the disease or medical condition the healthcare consumer group or organisation represents. The success of healthcare consumer groups in creating an environment for user-led medical and bioscience communication may be harder to replicate in other scientific disciplines. Fields such as physics, although affecting us every moment of our lives, does not seem to elicit as high an immediate emotional or personal bond as a health conditions do. With biomedical information there is an intrinsic bond and utility to that information that is tied up to our identities. ${ }^{24}$ With an increasingly "biomedicalised society" we can only assume an increasing trend for biomedical technologies, for better or for worse, to define who we are, at least physiologically and anatomically. ${ }^{24}$ In environmental areas, at the public interest level, there are various organisations that are driven by users and consumers, such as bird-watching clubs (in the biology and ecology fields), gemstone collectors (in the geology field) to collectives of users in more applied activities such as clubs catering for robotics and electronics enthusiasts (in the engineering and electronics fields). One factor that is prominent in the 
Alzheimers Australia Incorporated. URL: www.alzheimers.org.au

Arthritis Australia and affiliated state-based arthritis organisations. URL: www.arthritisaustralia.com.au/

Asthma Foundation Australia. URL: www.asthmaaustralia.org.au

Australian Crohns and Colitis Association. URL: www.acca.net.au

Australian Federation of AIDS Organisations. URL: www.afao.org.au

Breast Cancer Action Group Inc. URL: www.bcag.org.au

Cancer Voices Australia and affiliated state-based cancer organisations. URL:

www.cancervoicesaustralia.org.au

COTA Over 50s Ltd. URL: www.cotaover50s.org.au/

Federation of Ethnic Communities' Councils of Australia Inc. URL: www.fecca.org.au/

Health Consumers' Council WA (Inc). URL: www.hconc.org.au

ME/Chronic Fatigue Syndrome Association of Australia and affiliated state-based organisations. URL:

www.mecfs.org.au/

National Association of People Living with HIV/AIDS, Australia (NAPWA). URL: www.napwa.org.au

Parkinson's Australia Inc and affiliated state-based organisations. URL: www.parkinsons.org.au

Table 1. A list of some Australian healthcare consumer groups and their websites.

success of healthcare consumer organisations is the relatively high profile, continuous high levels of public and governmental support, and in some cases some commercial support afforded to these consumer organisations to enable the sustainability of their activities that does not seem to be afforded to other types of scientific user and consumer groups. For example, health supplement manufacturers and sporting organisations have given financial and media support over the years to cancer research campaigns, especially for breast cancer, in Australia.

\section{Independent medical information organisations}

Organisations such as the National Prescribing Service, ${ }^{25}$ the Health Issues Centre, ${ }^{26}$ and the Cancer Council Australia ${ }^{27}$ and its state counterparts, provide independent medical information to consumers and users of medicines. They are usually staffed by biomedical scientists and healthcare professionals. What organisations such as these do for the user-led production and sharing of scientific information is produce and disseminate information to the general public. While these organisations are not public "users" or "consumers", they provide an important source of reliable and understandable information for users and consumers, which in turn help to perpetuate a more knowledgeable public.

The role of the independent medical information organisation to the phenomenon of user-led production and sharing of medical information is partly as an information provider and partly as a facilitator of user communication. With the provision of appropriately targeted medical information to users and consumers we have seen empowerment of consumers and users to share and create knowledge networks of healthcare and medicine consumers. The empowerment of consumers in accessing understandable biomedical information makes consumers more confident about the medical field and can empower them to pursue further reading or research in the medical literature. An example of the medical information organisation improving the reach of medical information to diverse communities is the partnership between the National Prescribing Service and FECCA to provide translations of medical information for consumers in Australia in their "multicultural community quality use of medicines program". ${ }^{28}$ An interesting relationship between consumers and some of these medical information organisations is that consumers can also contribute to the policies, strategies, and advocacy activities of these organisations. There is a symbiotic relationship where communication of medical information is occurring back and forth between these groups.

Various avenues of popular media, which may be considered somewhat as independent medical information organisations, also feed consumers and users of medical information. On television (e.g. Discovery Health), websites (e.g. HealthInsite, ${ }^{29}$ which is an Australian Government initiative to provide health and medical information to the public), in magazines (e.g. Men's Health), and other media channels are easily accessible sources of information. Popular science publications that cater for more discerning users such as New Scientist, Australia's Cosmos Magazine, ${ }^{30}$ and Australasian Science ${ }^{31}$ regularly run articles on various scientific areas, including medical or health breakthroughs. 


\section{Consumer peer tutoring programmes}

With the increasing empowerment of healthcare consumers and users of medical services and products in Australia, there has also been the creation of consumer peer tutoring programmes. These are programmes where users of medicines tutor other new or less experienced users about how to use their medicines and about healthcare issues in general, and there are similar activities in other settings. ${ }^{32-35}$ In Australia there are a few reasons for these peer tutoring programmes coming into existence. One reason is due to the relatively low access to healthcare professionals due to living in rural areas where access to doctors or pharmacists is low, or living in areas with a low doctor-to-population ratio or low pharmacist-to-population ratio. These may be reasons for minimal opportunity for the users and consumers to get to know their new medicines or medical routines. Other reasons are that consumers may simply not understand the medical information even after speaking to a healthcare professional. Things like inadequate cultural and linguistic translations may prevent the proper dissemination of the relevant medical information to a consumer from a multicultural background, and this is something that organisations such as the NPS and FECCA mentioned previously are collaborating on to overcome. ${ }^{28}$ In Australia, more experienced users and consumers have seen this gap in the healthcare journey and acted to help newer consumers. Examples of peer tutoring do occur in Australia but are not recorded in the published science communication literature to this author's knowledge. There are some institutional reports that elaborate on this and other methods of communication though. $^{36,37}$ The fact that users and consumers can teach other users and consumers of health and medical information is testament to the power and effectiveness of user-led bioscience and medical communication.

\section{Email lists and online networks}

With an increasingly interconnected world, the use of email and online tools is very useful in sustaining the user-led production and sharing of scientific information. The importance of email and online tools to the biomedical and healthcare user and consumer is high in large networks of consumers. Examples of networks of users and consumers in the medical field include various health consumer organisations such as $\mathrm{CHF}$, and the various state-based and national Cancer Voices organisations. The members of these lists discuss medical issues very competently and create an environment where issues are debated. Examples of medical and scientific issues recently discussed via online networks include the quality of medical evidence, the scientific validity and use of complementary medicines, and the regulations of medical technologies within Australia.

The use of email lists and online networks is something that is common internationally in various medical information consumer and user organisations. International examples include the International Alliance of Patients' Organisations ${ }^{38}$ which has The Patients' Exchange Listserv, Consumers Advancing Patient Safety, ${ }^{39}$ and the WHO World Alliance for Patient Safety. ${ }^{40}$ The advantage of online networks is the dissemination and access to medical information from many more users and consumers around the world, and therefore enriching the knowledge of users who are geographically restricted so much more easily. This in some respects is a positive effect from what Thomas Friedman suggests as the "flattening of the world". However, not everyone has access to the technologies of the "flat world" yet. The drawback of online tools is that users from remote regions as well as elderly users may not have access to these avenues of communication or may not be adept at using these technologies. These are important demographics in user-led communication of medical information because they provide unique views and are usually very knowledgeable about medicines, health issues and issues pertaining to effective communication of medical issues. The penetration of the internet in Australia is relatively low compared to other OECD countries and is approximately $50 \%$ of households for rural and regional areas. ${ }^{41}$ This may be why many communications from user-led health consumer organisations still provide hardcopy communications for their membership - to maximise communication with those not able to access electronic communication tools. Some users may simply prefer hardcopy communications.

The use of email lists and online networks in other fields of user-led science communication is unclear, but it is probably the most easily utilised tool for users and consumers of scientific information to use to share ideas and information and create networks of similar users. Blogs and online groups (e.g. Facebook) are other online tools used for creating a virtual community. At present, it is unclear how consumers are using these tools to create and share medical information. It is unclear how strong the 
uptake of the use of these tools is and what impact these tools have on user-led science communication, particularly medical and bioscience communication.

\section{The positives and negatives of user-led medical and bioscience communication}

From the medical and bioscience field, the impact of the information being produced and shared has a strong personal element to it. Producers and consumers of the information must be wary of sensationalisation of this information in the public domain. ${ }^{13,14,42}$ With well-organised publicly-funded initiatives and networks, there tends to be fairly balanced information being shared. This can be in part due to the close partnership between government policy, research, and medical institutions with the public. ${ }^{4,43-45}$ There are mechanisms for incorporating the input of the public into decision-making. ${ }^{46}$ However, there needs to be caution about the use of publicly available scientific information to further the agenda of special-interest and lobbying groups, which could be used to advance potentially biased or unproven opinions or for scaremongering, in areas such as GMO, genetic screening, stem cell therapies and nanotechnologies. ${ }^{24,47-49}$

\section{Public empowerment in healthcare decision-making}

In the medical and bioscience fields there have been a few situations where there has been legitimate public backlash and negative sentiment, but also cases where there has been unjustified hype and scaremongering, with genetic technologies having received much negative reaction, especially for genetic therapies and testing. ${ }^{13,42,50}$ There is also observed tension between the knowledge of experts versus that of lay people. ${ }^{10}$ But this tension and power struggle may be simply due to a lack of communication resources and knowledge amongst and between professional and lay people, which results in barriers to consumer engagement. ${ }^{37,51-53}$ In the area of science communication, it is acknowledged that networking and shared learning could reduce these barriers to consumer empowerment and sharing of scientific and medical information. ${ }^{37,51-53}$ Another example of public empowerment have been the enquiries into the nutritional content of fast foods, which has seen fast food outlets reduce the fat and sugar content of many of their products, as well as now having to provide healthy alternatives (e.g. McDonalds restaurant chains). A bit of sensationalisation and creative license is taken when consumers go to extraordinary lengths to prove to other consumers the negative effects of a poor diet as was demonstrated by Morgan Spurlock in the 2004 movie Super Size Me. How scientific this human experiment was is debatable, but the power of a consumer sharing their experience and knowledge gained from that experience to other consumers is powerful and seemed to have been a catalyst for change for the menu at McDonalds restaurants in many countries to healthier items.

With the public more informed and empowered about scientific issues there has been more debate about genetic technologies and about who should decide to use them and how they should be used. ${ }^{54}$ Even for seemingly less effective technologies and therapies, such as complementary medicines, we see that informed public and consumer input into the regulatory processes is seeked. ${ }^{55}$ Combining biology, health and medicine, and agricultural sciences, is a strong and increasing user-led movement of organic nutrition, further purported by non-scientists and celebrities in the food and nutrition arena such as the British chef Jamie Oliver. What we see in many consumers of organic products and foods is an understanding of nutrition, health, and ecology (as well as plant and animal biology in highly educated consumers) combined with vast networks of consumers who share information on better nutrition and environmental issues that affect their health (e.g. pollution, soil health, conservation issues).

With the acknowledgement of consumer empowerment in medical and policy issues, and the ability for consumers to organise themselves into efficient and powerful advocacy groups, the emphasis has now shifted to how and when to engage these users of bioscientific and policy information for the public good. There has been consensus, including other fields apart from the medical and healthcare field, that consumers need to be engaged early in any consultations and decision-making processes. ${ }^{49,56,57}$ 


\section{Science for the people}

The examples of medical information being absorbed, created, and shared by users and consumers are examples of the role that science has for public good. It has been a sentiment that science is created for the public to use and for it to be disseminated for the betterment of humanity. ${ }^{46,58-60}$ The fact that biomedical information is being utilised by users and the public at various levels highlights the utility of scientific information and research and the effectiveness of its integration into people's lives. ${ }^{1,2,9,36,61,62}$ We see the effects on increasing the quality of the collective intelligence of a society when informed users and consumers are able to contribute to medical and healthcare debates and policies on various levels. ${ }^{1,2,4,9,35,43,44,52,60,62,63}$ The fact that in Australia, the use of Consumer Advisory Committees in hospitals, ${ }^{64}$ and of involving consumers in high-level policy-making processes ${ }^{65}$ is a positive step in medical consumer and user empowerment. The trend of increasingly medically informed citizens means that consumers are more able to contribute meaningfully to debates and decision-making. ${ }^{10,15,36}$ If nothing else, the example of bioscientific information being created and shared by users and consumers proves that science is not beyond the grasp of the public, and communicating science is not simply a top-down affair (i.e. from experts to the public), but can also be a bottom-up process (i.e. from consumers to experts and policy-makers).

\section{"Bioscientific” prejudice}

However, an insight into the user-led sharing and production of biomedical information can see some negative effects for a "scientific society". Because in the medical fields consumers of biomedical information are usually doing so because they have a personal interest in the particular information we see the creation of special interest and lobby groups for particular medical causes. There are senior consumers of biomedical information and political issues who act as gatekeepers of the information and champions of consumer engagement and share their knowledge with less experienced consumers. ${ }^{33,37}$ This helps to keep the user-led sharing and production of bioscientific information flowing in the public sphere. Where there are potentially negative effects of consumer-led control of biomedical information and policies is when there is what can only be called "competition" between disease groups and lobbies, as well as the fact that consumer groups are usually not like typical members of the public. ${ }^{10,11,66,67}$ Competition between medical consumer groups can occur due to competitive government funding for initiatives or research programmes for certain diseases or creating a higher public profile for a disease group. It almost seems as though the bioscientific information that empowered consumers about themselves and about what was happening in their lives creates a chasm between them and other people with different biomedical interests because of political and financial competition based on biomedical grounds (e.g. cancer competing with HIV/AIDS groups). What hypothetically happens is a sort of "bioscientific prejudice" against those who do not share the same medical experiences or biomedical interests as they do. This in some ways refers to the already noted "biomedicalisation" of society, and potentially another classification of people. ${ }^{24}$ The danger lies where a disease defines who someone is, and these consumers exclude others in their daily lives because they don't share in their similar biomedical or disease group interests.

\section{Abuse of positional power}

There is also another danger in the rise of consumer-created and shared medical information. This relates to the rise of consumer experts and the trust given to them because of their knowledge and position in the community. As well informed as consumers can be about the medical issues and the science behind them, we must remember that knowledge in the hands of anybody can be abused and misused. We must be wary that we are not transferring power from one set of medical information gatekeepers (e.g. the healthcare professionals) to another group (e.g. the medical information consumers), and simply perpetuating elite voices in health and medicine. ${ }^{68}$ Especially in health lobby groups and interest groups there can be an almost unquestioning trust in those consumers who have both the medical knowledge and personal experiences in the healthcare journey for whatever disease the lobby or interest group represents. In the public policy arena there is strong persuasive power of both scientific knowledge and 
the personal passion and experience that these consumers bring with them. The strength of combining biased and selective "scientific facts" and a strongly emotional personal story can be powerful political tools that could be used for unscrupulous ends. ${ }^{11}$ In highly emotionally charged issues, sometimes having a neutral scientific voice is called for to minimise sensationalisation and bias. What scientists can bring with them is the sometimes forgotten power and law upon which science is based - that of dispassionate objectivity, impartiality, and a continuous duty to question what they and everyone else currently knows and to adjust their beliefs when new scientific evidence is proven.

In the author's view, with the adoption of more accountability to the public of where medical research funding goes in Australia, and the increased public scrutiny of private and public research, the validity and quality of medical information reaching the public is achieving higher standards. With more users of the bioscientific information, and increasing general scientific literacy of the public, we may see higher levels of scrutiny with an increasingly educated and science-savvy public.

\section{Conclusion}

Some strategies employed by individuals, public groups, and consumers discussed here might be useful in other scientific fields for public communication of science and technology. The formation of specialised consumer groups that discuss medical and policy information, independent medical information organisations, consumer peer tutoring, and email lists and consumer networking events are user-led avenues that can be used to create and share biomedical information and to connect with more consumers. With an increasingly biomedicalised society and educated public, consumers of medical information are yielding more influence in the way bioscience is disseminated and absorbed by the general public. This user-led bioscience communication phenomenon is increasing the public consumer's knowledge of medicine as well as empowering them to take action in many arenas of their own health and medical policy.

\section{Notes and references}

Victorian Quality Council (2007), Consumer leadership. Report of the findings of a literature review and consultation process into consumer leadership, February 2007, D.o.H.S. Victoria ed., Rural and Regional Health and Aged Care Services Division, Melbourne. p. 1-78.

2 Victorian Quality Council (2007), Consumer leadership. A literature review, D.o.H.S. Victoria ed., Rural and Regional Health and Aged Care Services Division: Melbourne, p. 1-78.

3 E. Anderson, M. Shepherd, and C. Salisbury (2006), 'Taking off the suit': Engaging the community in primary health care decision-making, Health Expectations 9: 70-80.

4 Department of Human Services Victoria (2005), Consultation paper: Participation in your health service system, Department of Human Services Victoria, Melbourne.

5 T. Friedman (2007), The world is flat, 3.0: A brief history of the twenty-first century, Picador, USA.

6 National Library of Medicine, http://www.ncbi.nlm.nih.gov/pubmed/.

7 Public Library of Science, http://www.plos.org/.

8 D. Bowling (2001), Engaging citizens in the Danish health care sector, in Citizens as partners: Information, consultation and public participation in policy making, J. Caddy ed., Organisation for Economic Co-operation and Development, Paris. p. 107123 .

9 Health Canada (2000), Health Canada policy toolkit for public involvement in decision making, Health Canada: Ottowa.

10 D. Horey and S. Hill (2005), Engaging consumers in health policy, in Australian Institute for Health Policy Studies Health Policy Roundtable, Australian Institute for Health Policy Studies, Canberra.

11 M. Nisbet and C. Mooney (2007), Framing science, Science 316(5821): 56

12 A. Gunther and K. Schmitt (2004), Mapping boundaries of the hostile media effect, Journal of Communication 54(1): 55-70.

13 T. Caulfield (2004), Biotechnology and the popular press: hype and the selling of science, Trends in Biotechnology 22(7): 3379.

14

14 L. Rothenberg (1994), Biotechnology's issue of public credibility, Trends in Biotechnology 12(11): p. 435-438.

15 J. Gregory and Australian Institute of Health Policy Studies (AIHPS) (2007), Conceptualising consumer engagement: a review of the literature, in Consumer engagement in Australian health policy: Investigating current approaches and developing new models for more effective consumer participation, Australian Institute of Health Policy Studies (AIHPS): Melbourne. p. 1-69.

16 National Medicines Symposium, http://www.nps.org.au/all_events/all_events/national_medicines_symposium_2008.

17 Second Joint Medicines Policy Conference, http://www.medicinesaustralia.com.au/pages/page132.asp.

18 Australian Commission on Safety and Quality in Health Care, http://www.safetyandquality.gov.au/. 
19 Australian Commission on Safety and Quality in Health Care (2009), Discussion paper on achieving the directions established in the proposed national safety and quality framework, Australian Commission on Safety and Quality in Health Care, Sydney.

20 E. Einsiedel (2008), Public engagement and dialogue: a research review, in Handbook of Public Communication on Science and Technology, M. Bucchi and B. Smart eds., Routledge: London. p. 173-184.

21 Consumers Health Forum of Australia, http://www.chf.org.au.

22 Cancer Voices Australia, http://www.cancervoicesaustralia.org.au/.

23 Health Consumer Council, http://www.hconc.org.au/.

24 A.E. Clarke et al. (2003), Biomedicalization: Technoscientific transformations of health, illness, and US biomedicine, American Sociological Review 68(2): p. 161-194.

25 National Prescibing Service, http://www.nps.org.au.

26 Health Issues Centre, http://www.healthissuescentre.org.au/.

27 Cancer Council Australia, http://www.cancer.org.au/Home.htm.

28 National Prescribing Service and Federation of Ethnic Communities Councils of Australia, Multicultural community quality use of medicines program, http://www.fecca.org.au/MCQUM.cfm.

29 Health Insite. An Australian Government Initiative, http://www.healthinsite.gov.au/.

30 Cosmos Magazine Australia, http://www.cosmosmagazine.com/.

31 Australiasian Science Magazine, http://www.control.com.au/.

32 Expert Patients Program Community Interest Company (2009), Expert Patients Program CIC - Self managing long-term health conditions, available from http://www.expertpatients.co.uk/.

33 D. Johnstone and C. Campbell-Jones (2003), Skills for regeneration: Learning by community champions, Educe UK Department for Education and Skills, London.

34 M. Taylor et al. (2005), Making connections: An evaluation of the community participation programmes, Research Report 15, UK Office of the Deputy Prime Minister, London.

35 D. Johnstone et al. (2005), Neighbourhood Renewal Advisers: Skills and Knowledge Programme Evaluation Background Report 3, Educe UK Office of the Deputy Prime Minister, London.

36 J. Gregory and Australian Institute of Health Policy Studies (AIHPS) (2008), Consumer engagement in Australian health policy: Final report of the AIHPS research project, in Consumer engagement in Australian health policy: Investigating current approaches and developing new models for more effective consumer participation, Australian Institute of Health Policy Studies (AIHPS): Melbourne. p. 1-99.

37 A. Watson et al. (2004), Evaluation of the community champions fund, ASW Consulting, UK Department for Education and Skills, London.

38 International Alliance of Patients' Organisations, http://www.patientsorganizations.org/.

39 Consumers Advancing Patient Safety, http://www.patientsafety.org/.

40 WHO World Alliance for Patient Safety, http://www.who.int/patientsafety/en/.

41 Regional Telecommunications Independent Review Committee (2008), Regional telecommunicatons review: Framework for the future, Australian Government Attorney General's Department: Barton.

42 S. Cunningham-Burley (2006), Public knowledge and public trust, Community Genetics 9(3): p. 204-210.

43 National Health and Medical Research Council (2006), Guide to effective participation of consumers and communities in developing and disseminating health information, National Health and Medical Research Council Australian Government, Canberra.

44 Department of Human Services Victoria (2006), Doing it with us not for us, D.o.H.S. Victoria ed., Rural and Regional Health and Aged Care Services: Melbourne. p. 1-100.

45 D.T. Zallen (1994), The public as a partner at the laboratory bench, Trends in Biotechnology 12(4): 107-108.

46 R. Borchelt and K. Hudson (2008), Engaging the scientific community with the public, Science Progress, Spring/Summer: p. 78-81.

47 M. Powell (2008), Building citizen capacities for participation in nanotechnology decision-making: the democratic virtues of the consensus Conference model, Public Understanding of Science 17(3): 329-348.

48 J. Besley et al. (2008), Interpersonal discussion following citizen engagement about nanotechnology, Science Communication 30(2): 209-235.

49 T. Rogers-Hayden (2007), Moving engagement "upstream"? Nanotechnologies and the Royal Society and Royal Academy of Engineering's inquiry, Public Understanding of Science 16(3): 345-364.

50 J. Barnett, H. Cooper and V. Senior (2007), Belief in public efficacy, trust, and attitudes towards modern genetic science, Risk Analysis 27(4): 921-933.

51 L. Cairncross et al. (2002), Tenants managing: an evaluation of tenant management organisations in England, Office of the Deputy Prime Minister: London.

52 D. Hills et al. (2007), The Evaluation of the Big Lottery Fund Healthy Living Centres Programme, Tavistock Institute and Bridge Consortium: London.

53 J. Tunstill et al. (2005), Sure Start local programmes: Implications of case study data from the national evaluation of Sure Start, Children and Society 19: 158-171.

54 P. Sturgis, H. Cooper and C. Fife-Schaw (2005), Attitudes to biotechnology: estimating the opinions of a better-informed public. New Genetics and Society, 24(1): 31-56. 
55 Consumers Health Forum of Australia (2009), Submission to the Draft Guideline for Levels and Kinds of Evidence of Listed Medicines with Indications and Claims for Weight Loss, Consumers Health Forum of Australia:,Canberra. p. 8.

56 B. Wynne (2006), Public engagement as a means of restoring public trust in science--hitting the notes, but missing the music? Community Genetics 9(3): 221-220.

57 J. Wilsdon and R. Willis (2004), See-through science: why public engagement needs to move upstream, Demos, London.

58 E. Allen and L. Hood (2000), Biotechnology, inquiry, and public education, Trends in Biotechnology 18(8): 329-30.

59 E. Cohen et al. (2008), Public engagement on global health challenges, BMC Public Health 20(8).

60 K.G. Davies and J. Wolf-Phillips (2006), Scientific Citizenship and good governance: implications for biotechnology, Trends in Biotechnology 24(2): 57-61.

61 Australian Health Care Reform Alliance (2005), Action plan for health care reform in Australia, Paper IV: Community consultation and engagement, Australian Health Care Reform Alliance.

62 UK National Institute for Health and Clinical Excellence (NICE) (2008), Community engagement to improve health. NICE public health guidance 9, in NICE public health guidance, U. Nice ed., UK NICE, London, p. 1-91.

63 S. Oliver et al. (2004), Involving consumers in research and development agenda setting for the NHS: developing an evidencebased approach, Health Technology Assessment 8(15): 1-154.

64 B. O'Brien, A. Alderice and J. Hales, Evaluation of the effectiveness of the community advisory committees to boards of Victorian public health services, Final report. 2008, Department of Human Services Victoria and Health Outcomes International, Melbourne, p. 1-71.

65 A. Chisholm, K. Briggs and J. Askham (2009), Not NICE. Can PCTs engage patients and the public in commissioning new health technologies? Picker Institute Europe, Oxford, p. 1-45.

66 K. Jones, R. Baggot and J. Allsop (2006), Influencing the national policy process: The role of health consumer groups, Health Expectations 7: 18-28.

67 F. Scutchfield, L. Hall and C. Ireson (2006), The public and public health organizations: Issues for community engagement in public health, Health Policy 77(1): 76-85.

68 F. Scutchfield, C. Ireson and L. Hall (2004), The voice of the public in public health policy and planning: The role of public judgement, Journal of Public Health Policy 25(2): 197-205.

\section{Author}

Henry Ko currently works at the Centre for Clinical Effectiveness, located within the Monash Institute for Health Services Research at Southern Health, in Clayton, Australia. He has diverse experiences and interests in biomedical engineering, bioscience communication, economic development and the MDGs, innovation and development, evidence-based healthcare, socio-economic issues concerning emerging health technologies, and consumer engagement in medical issues. E-mail: henry.ko@med.monash.edu.au.

How TO CITE: $\quad$ H.C.H. Ko, The public production and sharing of medical information. An Australian perspective, Jcom 09(01) (2010) A03. 